\title{
Reactive Power Control for Grid Tied PVG System with ANN Based Transformerless Inverter
}

\author{
K.Ravikiran, K.S.Srikanth
}

\begin{abstract}
The Rise in power demand with growing population across the world has led to the development of renewable energy sources. Amongst all the renewable energy sources $P V$ power generation system proves to be more superior and efficient than other renewable sources. Recent innovations in transformerless inverters have proven to be efficient and reliable than conventional ones. The major difficulty in handling the transformerless inverter is the leakage currents, which is for the reason that parasitic capacitance is in between $P V$ array and ground. This leakage current leads to several protection issues along with unstable CM voltages. Here the recommendedtransformerless inverter aimed at grid connected $P V$ system has capability to reduce leakage currents. It also provides the required reactive power to the system to maintain constant CM voltage. To provide high quality current injection in to the grid, PR controller and fuzzy controller are used. In this study the detailed analysis of the operating modes of the H6 PV transformer less inverter system, investigation of the leakage currents and outcomesobtained in MATLAB simulation are to be presented.
\end{abstract}

Key Words: Common mode (CM), parasitic capacitance, reactive power, ANN controller, Transformer less inverter.

\section{INTRODUCTION}

With the rapid growth in population the demand for electrical power has been increasing and there has been a limitation on usage of natural resources. In order to meet the electrical power demand there has been great interest towards renewable energy sources[1]. Among all the renewable sources solar power is measured to be the better in order to meet the demand since it is pollution free and inexhaustible.With the rapid increase in power electronic devices and incentive beneficiary from the government, PV module price decreases, and so grid-connected PV systems plays an important role in distributed power generation.Typically galvanic isolated transformers are used in grid connected PV machine for protection reason. Galvanic isolation prevents DC current injection into the grid and the leakage currents between grid and PV module are reduced [2]. By the usage of high frequency transformers at the DC aspect and low frequency on inverter facet the overallperformance of the system is decreased. In order to overcome this problem transformerless grid tied with PV system is employed.

In this paper a new scheme of grid connected PV system with full bridge topology inverters are presented under low frequency transformer. With the help of this galvanic

Revised Manuscript Received on October, 2019

K.Ravikiran, Mtech Research scholar, Dept of Electrical and electronics engineering, KL Deemed To be University, Green Fields,Vaddeswaram,Vijayawada, Andhra Pradesh, India. Email:krk4future@gmail.com

K.S.Srikanth, Professor, Dept of Electrical and electronics engineering, KL Deemed To be University, Green Fields,Vaddeswaram, Vijayawada, Andhra Pradesh, India. Email:-srikanth.dsd@ gmail.com

isolation [3], it reduces the usage of inverter filter requirement and also eliminates the compliance of electromagnetic interference. Though, converters implanting frequency of the transformerwith $50 \mathrm{~Hz}$ ishugeandtransformeris accounted upto 1-2\% of power loss.

Aimed at the above reasons, researchers arelively in the study of results for removing line frequency transformer, with a view towards getting maximum efficiency deprived of increase in the cost of converter. The key problem that ascends when you suspends the low frequency transformer is remain at the place of parasitic capacitance amongst solar cells andmetallic frame of Panel [4]. This suggests that leakage current to ground and it can drifted to resonant circuit is collectedthe line conductors, grounding of MV/LV distribution transformer plus the parasitic capacitance of the PV field. Uncertainty,modest full-bridge is used deprived of coupling transformer or elsedefinedvariety strategy, highfrequency common mode voltage differences at converter output cause abnormal stages of earth leak current, whichmake EMI, reduces the security of the arrangement and reason the interruption of device remain to residual current device (RCD).

By removal of galvanic isolated transformer, the leakage currents between grid and PV module are increases, the parasitic capacitance effect occurs and it leads to common mode voltage fluctuation at grid side [5]. This common mode voltage fluctuation be contingent on the switching scheme and topology structure, hence which leads to capacitive leakage currents. These leakage currents increases the grid harmonic currents and system losses. To inject reactive power into system, this PV inverter is interfaced with grid. In recent international regulations certain rules have been imposed regarding minimum reactive power handling by grid-tied PV inverter system.

Previously transformerlessH-Bridge inverter is utilized for PV System. The basic simple H-Bridge PV transformer less inverter is shown in figure 1.The principle benefit of this topology is potential to generate reactive to the grid. The main disadvantage of this device is the bipolar pulse width modulation to avoid commonplace mode voltage and excessive switching losses in IGBTs [7].

A High Efficient Reliable Inverter Circuit (HERIC) topology has been utilized to overcome these problems. High Efficient Reliable Inverter Circuit (HERIC) topology in figure 2. For better reduction of core and switching losses, the $\mathrm{H} 6$ topology is implemented with unipolar. When HERIC topology operated under Reactive Power Generation, the MOSFET switches cause the reverse recovery voltage issues [8]. 
Another H5 transformer less topology show in figure 3 which is make from fig1 throughaddition an second switch at the at DC side of the full bridge inverter. For example when this system preform with input voltage $345 \mathrm{~V}$ dc and switching frequency $16-\mathrm{kHz}$ then system efficiency has 98\%.But, this topology consumesgreattransmission losses due to that the current necessity conduct over3 switches in series throughoutactive segment [9]. Every other drawback of the H5 is line frequency switchesi.e., S1, S2 can`t make the use of MOSFET gadgets due to fact that the MOSFET frame diodeis gradual reverse recovery.

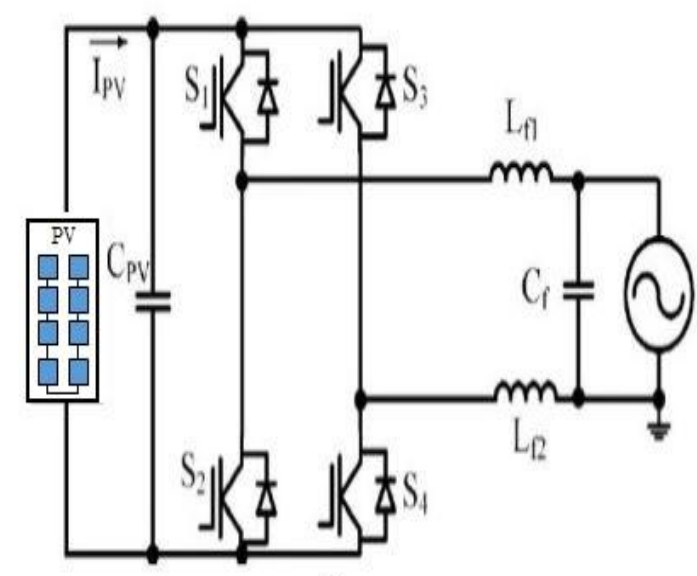

Fig.1.Topology of H-Bridge inverter [6]

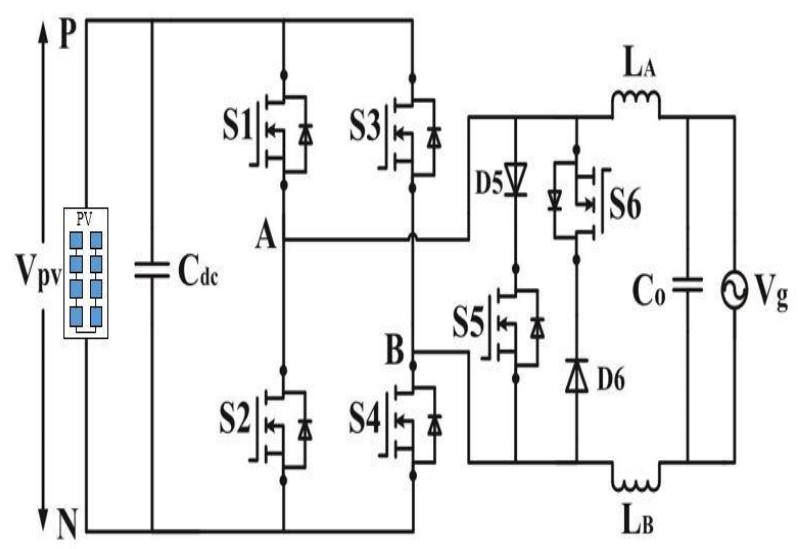

Fig. 2. HERIC inverter topology [8]

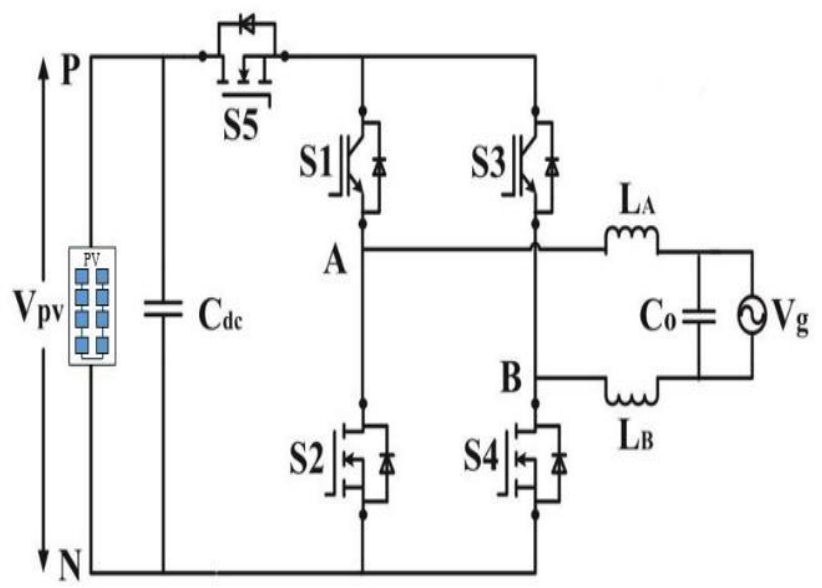

Fig.3. H5 inverter topology [9]

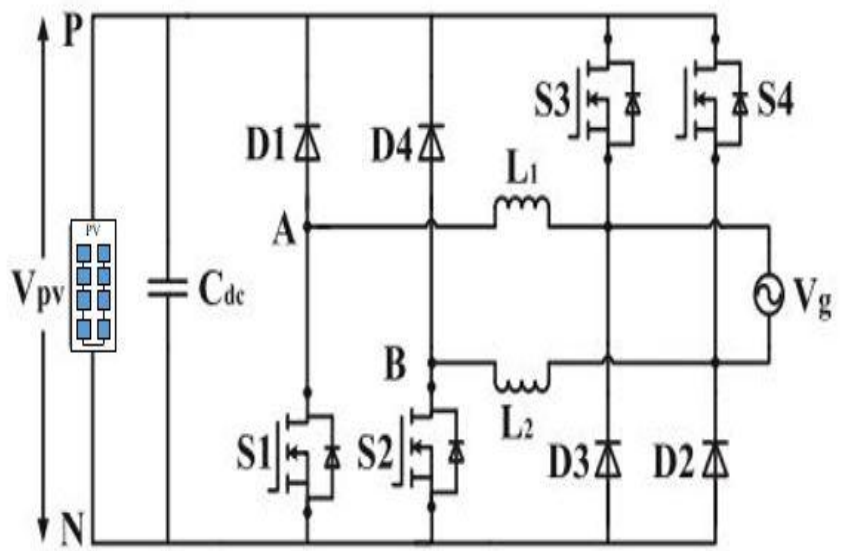

Fig .4.Symmetrical H6 inverter topology [10]

When we are capable of developed a transformerless inverter predominant troubles are taken into consideration.one of the trouble for an excessive effectiveness and consistencytransformerless PV inverter remainsas a way to gain great performance above an extensive load range is essential to use MOSFET switches for all switching devices [11]. Some otherdifficulty is that the inverter need to no longer ensure any shoot-via problems aimed atgreater reliability. A good way towardsdiscourse these main issues, a different inverter topology is projected for phase transformerless PV grid- coupledsystems.

The important function meant for grid coupled photovoltaic systems are generate real power and compensation of reactive power. This paper implemented with two current controllersi.e Fuzzy controller and PR controller. These current controllers are effectively control grid current and also maintain power flows between grid and system. The PR controller can maintain the grid current in phase through the grid voltage by the inverter, therefore unity power factor is achieved. The $\mathrm{PR}+\mathrm{HC}$ controllers are used to minimize lower order abnormal harmonics components existing in inverter output current, also these are gives great gain at resonant frequency. Therefore the system study state error reduce to zero. Due to this THD value of the system has been decreased. Therefore these controllers can reducing harmonic currents rejection and steady state errors as compared to the PI controllers.

\section{H6 TOPOLOGY AND OPERATING PRINCIPLE}

\subsection{Circuit configurations}

The H6 transformerless inverter topology shows in Figure 5 and its consists of 6 MOSFETs (S1-S6) along with 6 Diodes(D1-D6). The coupled inductors are $\mathrm{L}_{1 \mathrm{~A}}, \mathrm{~L}_{2 \mathrm{~A}}, \mathrm{~L}_{1 \mathrm{~B}}$, $\mathrm{L}_{2 \mathrm{~B}}, \mathrm{~L}_{1 \mathrm{~g}}, \mathrm{~L}_{2 \mathrm{~g}}$ form the LCL filter adopted to gridand signifies the input is de voltage in addition de link capacitor. In H6 topology the MOSFETs body-diodes contains of low reverse- recovery problems afteradding the reactive power into the grid [12].in order to reduce issues present topology developed with high reliability and efficiency. The 
suggestedtopologyalsocomprises of unipolar SPWM through 3 level output voltage.

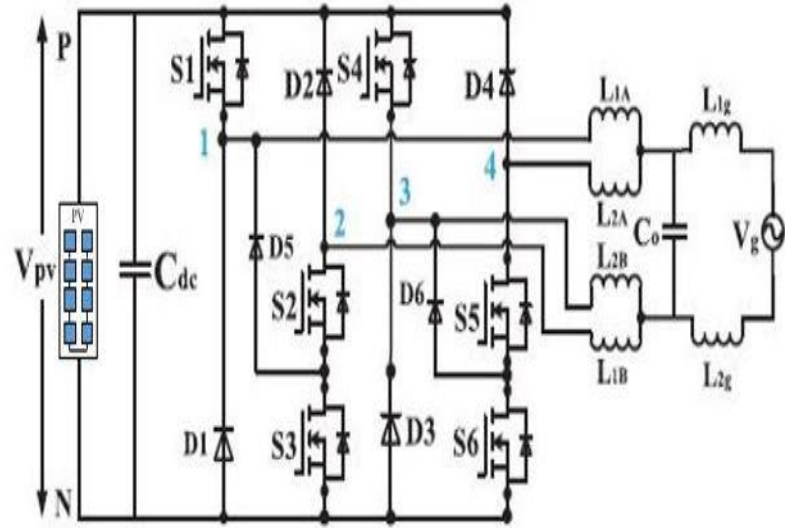

Fig.5. (a) H6 topology [12]

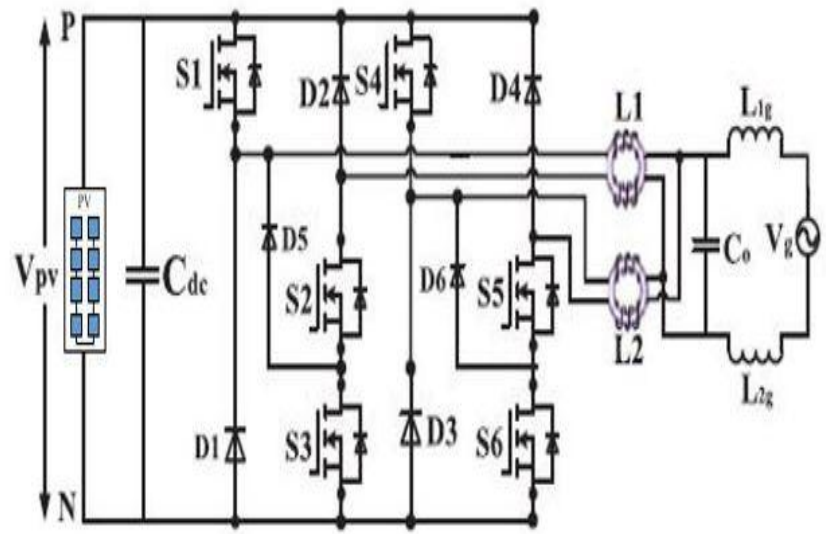

Fig. 5(b).H6 Circuit with coupled inductor

\subsection{Principle of Operation of H6 topology}

The switching pattern of suggested topology is in Fig.6 In this MOSFETs S1,S2,S3,S4,S5,S6 signifies main switches and their operating gate signals $\mathrm{G}_{\mathrm{s} 1}, \mathrm{G}_{\mathrm{s} 2}, \mathrm{G}_{\mathrm{s} 3}, \mathrm{G}_{\mathrm{s} 4}, \mathrm{G}_{\mathrm{s} 5}, \mathrm{G}_{\mathrm{s} 6}$ are correspondingly. The principle of operation of the suggested topology is categorized into four sections as shown in Fig.5. The proportional operation of the high-quality and the -ve halve cycle of the grid contemporary are identical, consequently right here positive half of cycle has discussed. But then the -ve halve of operation is shown in Fig.7.

Region I: In region I, the voltage of a grid $\left(\mathrm{V}_{\mathrm{g}}\right)$ and the grid current $\left(\mathrm{I}_{\mathrm{g}}\right)$ are $+\mathrm{ve}$. All through the duration inside the region I, S2 continually on, though S1 \& S3 synchronously and S5 opposite commutate with great switching frequency. There are constantly states that produce the output voltages are in two states i.e $+\mathrm{V}_{\mathrm{pv}}$ and zero.

State 1( $\left.\mathbf{T}_{0}: \mathbf{T}_{1}\right)$ : At $\mathrm{t}=\mathrm{T}_{0}$, the switches $\mathrm{S} 1 \&$ S3remain switched on and current via inductor rises over grid as shown in Fig.7(a). Now this time interval, the voltages $V_{1 \mathrm{~N}}$ and $\mathrm{V}_{2 \mathrm{~N}}$ may stand define as: $\mathrm{V}_{1 \mathrm{~N}}=+\mathrm{V}_{\mathrm{pv}}$ and $\mathrm{V}_{2 \mathrm{~N}}=0$, consequently the output voltage of inverter $\mathrm{V}_{12}=\left(\mathrm{V}_{1 \mathrm{~N}^{-}} \mathrm{V}_{2 \mathrm{~N}}\right)$ $=+\mathrm{V}_{\mathrm{PV}}$

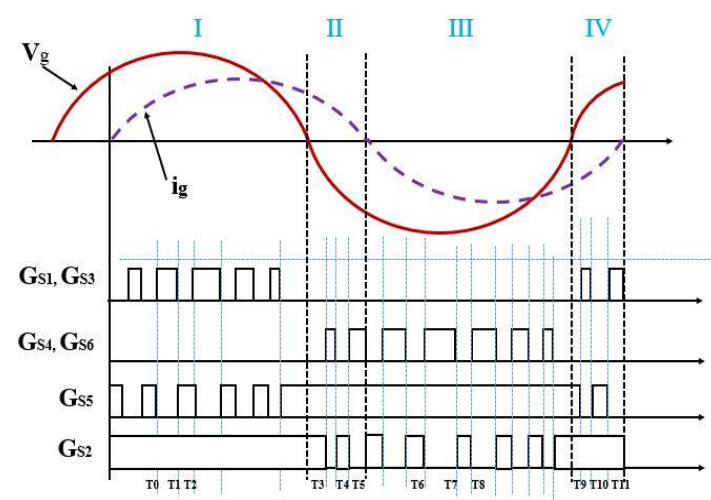

Fig.6.The Switching configuration of this projected topology

State $2\left(\mathbf{T}_{1}: \mathbf{T}_{2}\right)$ : While the switches $\mathrm{S} 3$ and $\mathrm{S} 1$ are becameoff, the current passes through inductor freewheels via D5 and $\mathrm{S} 2$. At present this state, $\mathrm{V}_{1 \mathrm{~N}}$ drops and $\mathrm{V}_{2 \mathrm{~N}}$ rises till their values are identical. Hence, the voltages $V_{1 N}$ and $V_{2 N}$ become: $\mathrm{V}_{1 \mathrm{~N}}=\mathrm{V}_{\mathrm{PV}} / 2$ and $\mathrm{V}_{2 \mathrm{~N}}=\mathrm{V}_{\mathrm{PV}} / 2$ and inverter output voltage is $\mathrm{V}_{12}=0$.

Region II:Currently, inverter final voltage exists negative, however, current remains to be +ve. All through the period of this range, S5 is constantly on, even as S6 \& S4 synchronously and S2 opposite commutate with great switching frequency. Here are also two states that provide the output voltage of $-\mathrm{V}_{\mathrm{PV}}$ and zero. The negative $1 / 2$ cycle operated in states to produce the output voltage of $-\mathrm{V}_{\mathrm{PV}}$ and 0 .

State 3(T3:T4):Going on the state 3, the MOSFETs S6 and $\mathrm{S} 4$ are on and clear out inductors remain demagnetized. For that inverter final voltage is -vethen the grid current rests positive; consequently, the cuurent through the inductor is enforced to freewheeledover the D1 and D2 diodes thenfalls unexpectedly intended forcontinuing the inverse voltage as shown in Fig. 7(c). The voltages $V_{1 \mathrm{~N}}$ and $\mathrm{V}_{2 \mathrm{~N}}$ can be well-defined as $\mathrm{V}_{1 \mathrm{~N}}=0$ and $\mathrm{V}_{2 \mathrm{~N}}=+\mathrm{V}_{\mathrm{PV}}$, thus the inverter output voltage $\mathrm{V}_{12}=\left(\mathrm{V}_{1 \mathrm{~N}}-\mathrm{V}_{2 \mathrm{~N}}\right)=-\mathrm{V}_{\mathrm{PV}}$.
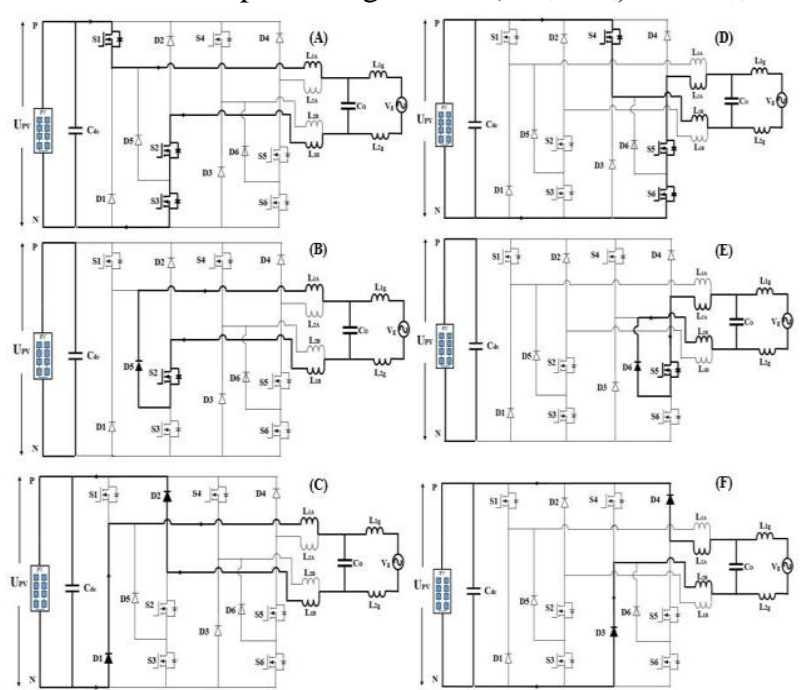

Fig.7.Principle of operation of H6circuit (a) state 1 (b) state 2 (c) state 3 (d) state 4 
State 4(T4:T5). When $\mathrm{t}=\mathrm{T} 4$, the switches S6 and S4 are switched off and S2 is turned-on. Consequently, the current allows over D5 and S2 like as per state 2 .Fig. 7(b) can be mentioned as equivalent circuit in inductor. This state is termed as energy storage mode. Then voltages $\mathrm{V}_{1 \mathrm{~N}}$ and $\mathrm{V}_{2 \mathrm{~N}}$ could be: $\mathrm{V}_{1 \mathrm{~N}}=\mathrm{V}_{\mathrm{PV}} / 2$ and $\mathrm{V}_{2 \mathrm{~N}}=\mathrm{V}_{\mathrm{PV}} / 2$, and thus the

The Photo voltaic module yields a chargeable electrical The Photo voltaic module yields a chargeable electrical area which faces a stranded frame. Due to this capacitance remainsmade between the grounding grid and PV Module. Consequently the capacitance ascendsas unwanted side effect, and is also denoted as parasitic capacitance. Due to theabsence of galvanic partingamong the grounded grid also the Photovoltaic Panel, a Common Mode resonant circuit is to be formed [13]. An alternating Common mode voltage to be predicated in this topology constructionplus control layout, due to this resonant circuit formed, and it causes the high ground leakage current flows through the circuit. so as to research the $\mathrm{CM}$ features, the equivalent circuit of suggestedtopology as shown in Fig. 8 may drawn, where $\mathrm{V}_{1 \mathrm{~N}}, \mathrm{~V}_{2 \mathrm{~N}}, \mathrm{~V}_{3 \mathrm{~N}}$ and $\mathrm{V}_{4 \mathrm{~N}}$ exist the managed source voltage is to be coupled to the -ve terminal $\mathrm{N}, \mathrm{L}_{\mathrm{CM}}$ and $\mathrm{C}_{\mathrm{CM}}$ exist the capacitance, and $\mathrm{Z}_{\mathrm{G}}$ is grid impedance. At the period of +ve cycle, the switches S4 and S6 stay continually switched off. An end outcome, the controlled voltage assets $V_{3 N}$ and $V_{4 N}$ are zero and can be removed. As stated by the definition of common mode $(\mathrm{CM})$ and differential-mode (DM) voltage:

$$
\begin{aligned}
& \mathrm{V}_{\mathrm{CM}}=1 / 2\left(\mathrm{~V}_{1 \mathrm{~N}}+\mathrm{V}_{2 \mathrm{~N}}\right) \\
& \mathrm{V}_{\mathrm{DM}}=\mathrm{V}_{1 \mathrm{~N}}-\mathrm{V}_{2 \mathrm{~N}}
\end{aligned}
$$

Solve (1) and (2) equations, $\mathrm{V}_{1 \mathrm{~N}}$ and $\mathrm{V}_{2 \mathrm{~N}}$ can be stated asfollow

$$
\begin{aligned}
& V_{1 N}=V_{C}+1 / 2 V_{D M} \\
& V_{2 N}=V_{C^{-}}-1 / 2 V_{D M}
\end{aligned}
$$

Nowto explain the Common mode model at switching frequency, equations (3) and (4) arechangedintendedforbridge-leg in Fig.7. In this the grid has frequency of supply voltage, therefore the effect of grid happening on the leakage current may not noted. The Differential Mode capacitor $\mathrm{Co}$ is eliminated because it indicates not at all impact happening the leakage current [2],[14]. Therefore, reformed structure of this topology used for+ve half cyclebe drawn as Fig.9. At last,model of this topology for +ve half cycle is derived in Fig.10. In Fig.10, the resultingequation of whole $\mathrm{CM}$ voltage can easilyresulting as:

$$
\mathrm{V}_{\mathrm{tCM}}=\mathrm{V}_{\mathrm{CM}}+\frac{V_{D M}}{2}\left(\frac{L_{2}-L_{1}}{L_{2}+L_{1}}\right)
$$

Where $\mathrm{V}_{\mathrm{tCM}}$ represent total $\mathrm{CM}$ voltage, and $\mathrm{L}_{1}=\mathrm{L}_{1 \mathrm{~A}}$ $+\mathrm{L}_{1 \mathrm{G}}$ and $\mathrm{L}_{2}=\mathrm{L}_{1 \mathrm{~B}}+\mathrm{L}_{2 \mathrm{G}}$. In this inverter when $\mathrm{L}_{1 \mathrm{~A}}=\mathrm{L}_{2 \mathrm{~A}}$ and $\mathrm{L}_{1 \mathrm{G}}=\mathrm{L}_{2 \mathrm{G}}$ aimed nicelyplanned circuit through symmetrically dependent magnetics, equation (5) may be modified as

follows:

$$
\mathrm{V}_{\mathrm{tCM}}=\mathrm{V}_{\mathrm{CM}}=\frac{1}{2}\left(\mathrm{~V}_{1 \mathrm{~N}}-\mathrm{V}_{2 \mathrm{~N}}\right)
$$
inverter output voltage, $\mathrm{V}_{12}=0$.

\section{HIGH FREQUENCY CM MODEL OF THE H6 TOPOLOGY FOR LEAKAGE CURRENT ANALYSIS} Common Mode inductor and capacitor, $\mathrm{C}_{\mathrm{PVG}}$ is parasitic

In keeping with the precept operation of present topology provided, the entire (CM)common mode voltages may calculated for every half cycle operation as follows:

State $1: \mathrm{V}_{\mathrm{tCM}}=\frac{1}{2}\left(\mathrm{~V}_{1 \mathrm{~N}}+\mathrm{V}_{2 \mathrm{~N}}\right)=\frac{1}{2}\left(\mathrm{~V}_{\mathrm{pv}}+0\right)=\frac{1}{2} \mathrm{~V}_{\mathrm{pv}}$

State $2: \mathrm{V}_{\mathrm{tCM}}=\frac{1}{2}\left(\mathrm{~V}_{1 \mathrm{~N}}+\mathrm{V}_{2 \mathrm{~N}}\right)=\frac{1}{2}\left(\frac{1}{2} \mathrm{~V}_{\mathrm{pv}}+\frac{1}{2} \mathrm{~V}_{\mathrm{pv}}\right)=\frac{1}{2} \mathrm{~V}_{\mathrm{pv}}$

State $3: \mathrm{V}_{\mathrm{tCM}}=\frac{1}{2}\left(\mathrm{~V}_{1 \mathrm{~N}}+\mathrm{V}_{2 \mathrm{~N}}\right)=\frac{1}{2}\left(0+\mathrm{V}_{\mathrm{pv}}\right)=\frac{1}{2} \mathrm{~V}_{\mathrm{pv}}$

State $4: \mathrm{V}_{\mathrm{tCM}}=\frac{1}{2}\left(\mathrm{~V}_{1 \mathrm{~N}}+\mathrm{V}_{2 \mathrm{~N}}\right)=\frac{1}{2}\left(\frac{1}{2} \mathrm{~V}_{\mathrm{pv}}+\frac{1}{2} \mathrm{~V}_{\mathrm{pv}}\right)=\frac{1}{2} \mathrm{~V}_{\mathrm{pv}}$

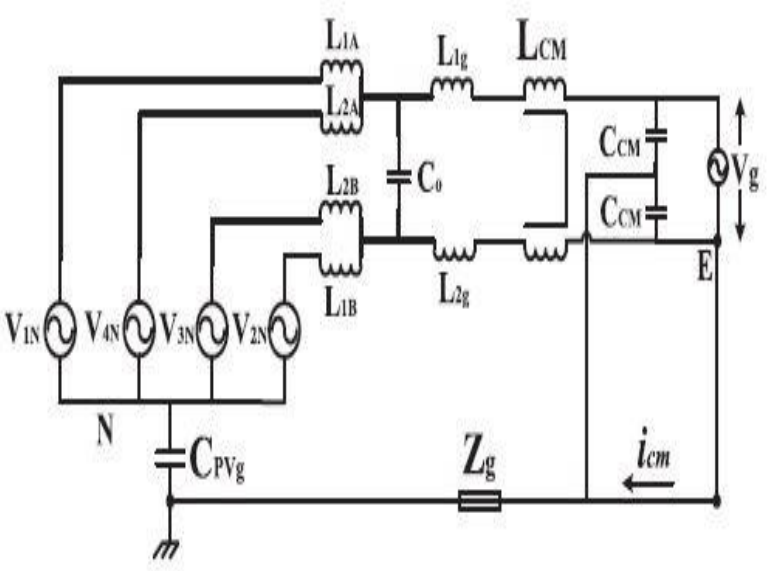

Fig.8.Equivalent Common Mode model of the suggested topology.

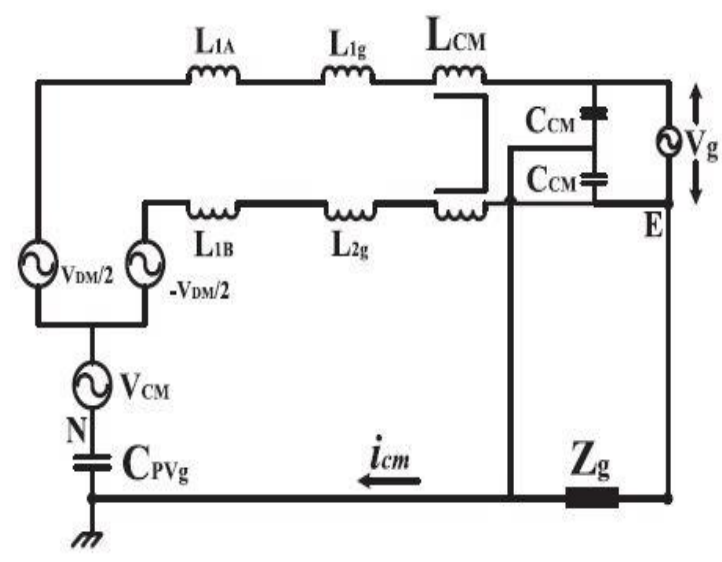

Fig.9. Basicsimplified Common Mode model at switching frequency for +ve half cycle.

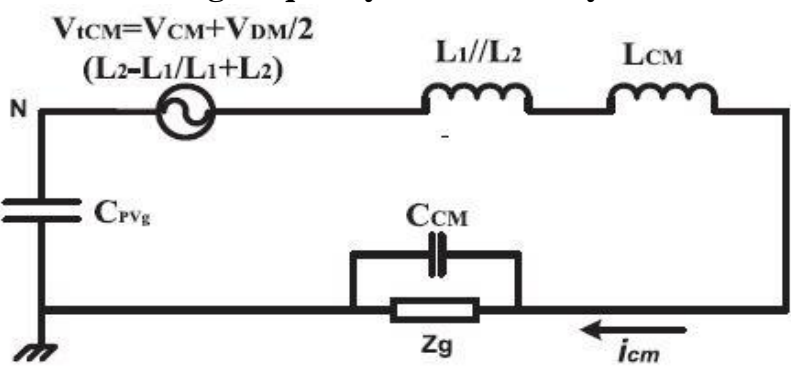

Fig.10.Equivalent single loop CM model. 
It`sperfect from equations (7) to (10) thatwhole(total) Common mode voltage for present topology is retained same at $\mathrm{V}_{\mathrm{PV}} / 2$ for the duration of +ve half cycle operation. Similarly, full CM voltage intended for-ve half cycle operation is calculated also discovered to be regularat $\mathrm{V}_{\mathrm{pv}} / 2$ because of the regularity of the operation for the corrupt $\&$ advantageous half cycle of grid present day. The most effective difference is the initiation of various energy devices. For this reason, it could be précisedto be whole CM voltage throughout the complete grid cycle is stored equal, lowering ground leakage current.

\section{CONTROLLER DESIGN}

The controlling structure of the suggested topology has shown in fig.11. This contains orthogonal signal generator (OSG) gadget for calculations of lively and reactive power of the gadget, fuzzy logic controller [14] for grid current controlling, and SPWM technology block [6].

In single phase grid related transformerless inverter, two controllers may evolved. One of the controller is fuzzy logic controller (FLC) and second one is proportional resonant current controller (PRC). These current controllers plays an important role in current injected into the grid with less harmonic content when the power interchange among the system and grid. $\operatorname{Ig} \alpha$ reference can control actual power,as well the orthogonal component of $\operatorname{Ig} \beta$ reference control the reactive power $\mathrm{Q}$ of device by grid. Consequently the decoupled governor of real and reactive powers be performed [12],[15],[16].

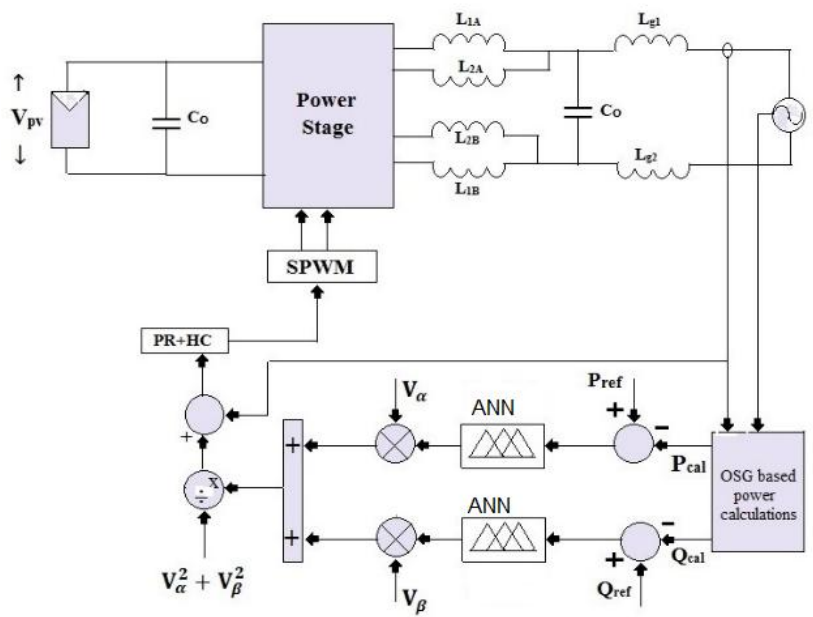

Fig.11.Block diagram for system control with ANN controller.

\subsection{Artificial Neural Networks}

Figure 12 denotes the elementarydesign of ANN, in this an unseenlayer is indicated by circle, adaptive node is denoted by square. In this constructionunseen layers are existingamong input and output layer, these nodes are operational as membership functions and rules are obtained depends on if-then statements are excluded. For minimalism, we areallowing for studying ANN have 2 inputs and 1 output. In present network, each neuron and element of input vector $\mathrm{p}$ are coupled with weight matrix W.

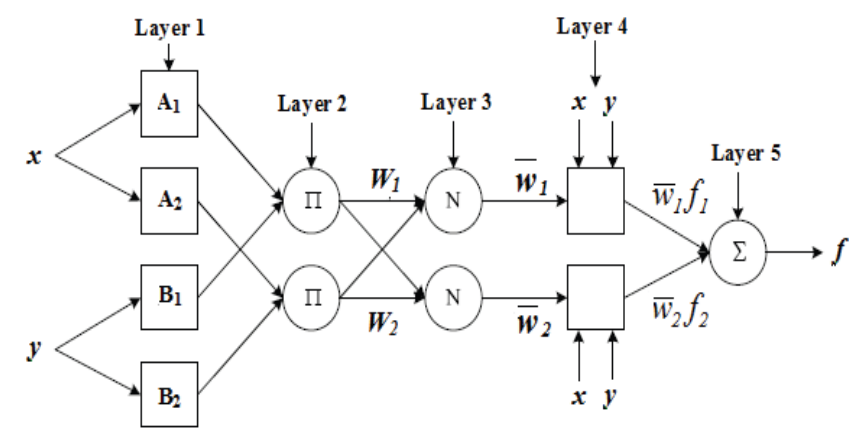

Fig.12. Architecture of the ANN for 2-input multilayer network

Where 2 crisp inputs are $\mathrm{x}$ and $\mathrm{y}$, the linguistic variables relatedwith node functions i.e., $\mathrm{Ai}$ and $\mathrm{Bi}$. The system is having total of 5 layers is in Figure 12.

procedure for executing ANN:

1. Recognize the number of input and outputs in normalize manner in the range of $0-1$.

2. Assume number of input stages.

3. Recognize number of unseen(hidden) layers.

4. Using transig and poslin commands make a feed forward network.

5. Assume learning rate would be 0.02 .

6. Take the number of iterations.

7. Take goal and train the system.

9.Create the simulation block, using 'genism' command.

\subsection{Proportional Resonant Current Controller}

The block representation of Proportional Resonant controller by way of harmonic current compensator depicts in Fig.13 the transfer function of essential contemporary controller are $\mathrm{Gc}(\mathrm{s}), \mathrm{Gh}(\mathrm{s})$ and $\mathrm{Gd}(\mathrm{s})$, harmonic compensator, and inverter respectively.

The Proportional resonant controller is employed in fixed frame that is not identicalfrom the normal PI controller. Due to no transformation from fixed frame to synchronous frame, the addition pattern of present controller stands simple. Designed forall these cases, processor which is less in cost that is used.Moreover, when grid imbalances or a sensing error happens, this present controller is more robust than PI controller. Particularly, the PR controller is appropriate for constant frequency operation inside the gridtied system. Commonly, the PI controller had drawbacks to decreasesteady state error in fixed reference frame [13],[14]. This controller structure has gottenknowledge due to ability of eliminating steady-state error when regulating sinusoidal signals. Furthermore, the modest execution of a harmonic compensator devoid of any counter cause on the controller results prepare the controller as well become for grid linked systems. The transfer function of the PR controller is defined below:

$$
G_{c}(s)=K_{p i}+K_{i i} * \frac{n}{s^{2}+w^{2}}
$$




$$
\begin{gathered}
G_{h}(s)=\sum_{h=3,5 \ldots \ldots . .} \frac{K_{i h} s}{s^{2}+\left(h w_{o}\right)^{2}} \\
G_{d}(s)=\frac{1}{1+1.5 T_{s} s}
\end{gathered}
$$

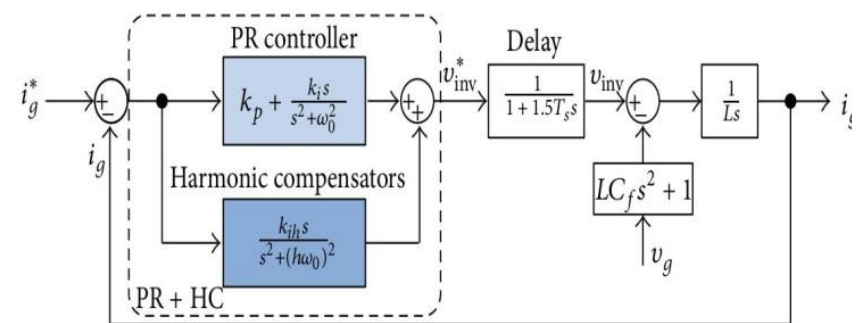

Fig.13.ThePR controller with harmonic compensator

In the sense $K_{\mathrm{pi}}$ and $\mathrm{K}_{\mathrm{ij}}$ are $\mathrm{P}$ and $\mathrm{R}$ gains, $\mathrm{W}_{0}$ is fundamental frequency, $K_{i h}$ R-gain at $n^{\text {th }}$ order harmonic, $h$ is harmonic order, and $\mathrm{T}_{\mathrm{s}} \mathrm{issampling}$ period.

\section{SPECIFICATIONS OF SYSTEM}

Table 1: System parameters

\begin{tabular}{|l|l|}
\hline Inverter Parameter & Value \\
\hline Input Voltage & $400 \mathrm{~V} \mathrm{DC}$ \\
\hline Grid Voltage /Frequency & $230 \mathrm{~V} / 50 \mathrm{~Hz}$ \\
\hline Switching Frequency & $20 \mathrm{kHz}$ \\
\hline DC bus capacitor & $470 \mu \mathrm{F}$ \\
\hline Filter Capacitor & $2.2 \mu \mathrm{F}$ \\
\hline $\begin{array}{c}\text { Filter Inductor } \mathrm{L}_{1 \mathrm{~A}}, \mathrm{~L}_{2 \mathrm{~A}}, \mathrm{~L}_{1 \mathrm{~B}} \\
, \mathrm{~L}_{2 \mathrm{~B}}\end{array}$ & $1 \mathrm{mH}$ \\
\hline Filter Inductor $\mathrm{L}_{\mathrm{g} 1}, \mathrm{~L}_{\mathrm{g} 2}$ & $0.5 \mathrm{mH}$ \\
\hline $\mathrm{PV}$ Parasitic Capacitor & $75 \mathrm{nF}$ \\
$\mathrm{C}_{\mathrm{PV} 1}, \mathrm{C}_{\mathrm{PV} 2}$ & \\
\hline
\end{tabular}

\section{SIMULATION RESULTS}

The Analysis of this transformerless inverter topology was performed by using MATLAB/SIMULATION SOFTWARE.Parameters are considered in simulation are given in Table $I$. in this simulation PV module is replaced with $400 \mathrm{~V}$ DC Voltage source.CPV1,CPV2 are parasitic capacitances between the PV module and ground, which is emulated using thin film capacitor of $75 \mathrm{nf}$. In this phase, assessment of unlike parameters along with voltage of the inverter, CM voltage, leakage contemporary and the performance of H6 topology underneath adjustments of reactive and actual energy are mentioned.
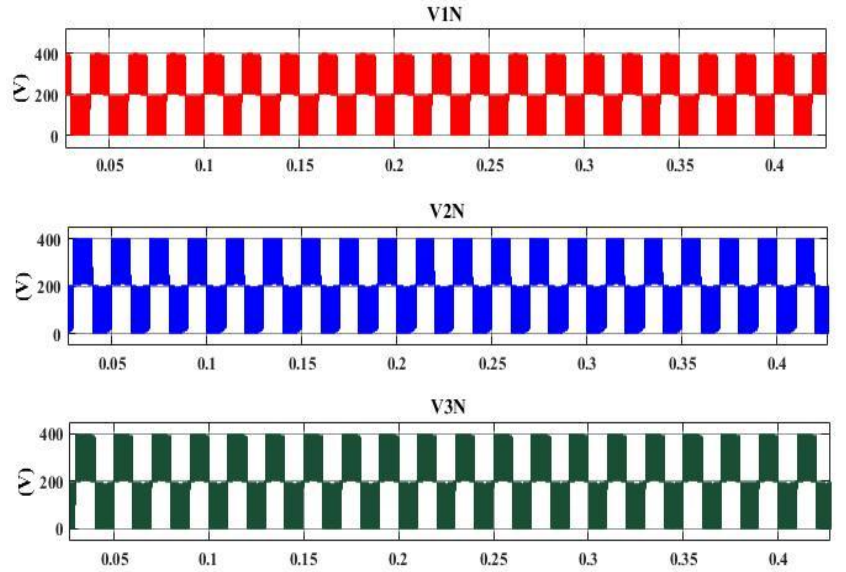

V4.

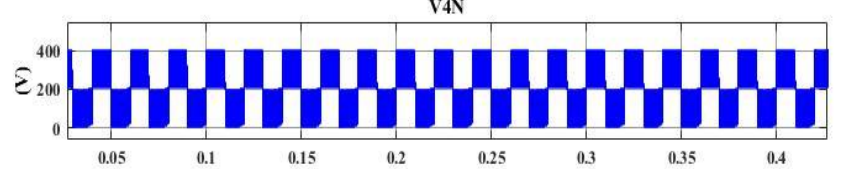

$(\mathrm{V} 1 \mathrm{~N}+\mathrm{V} 2 \mathrm{~N}) / 2$
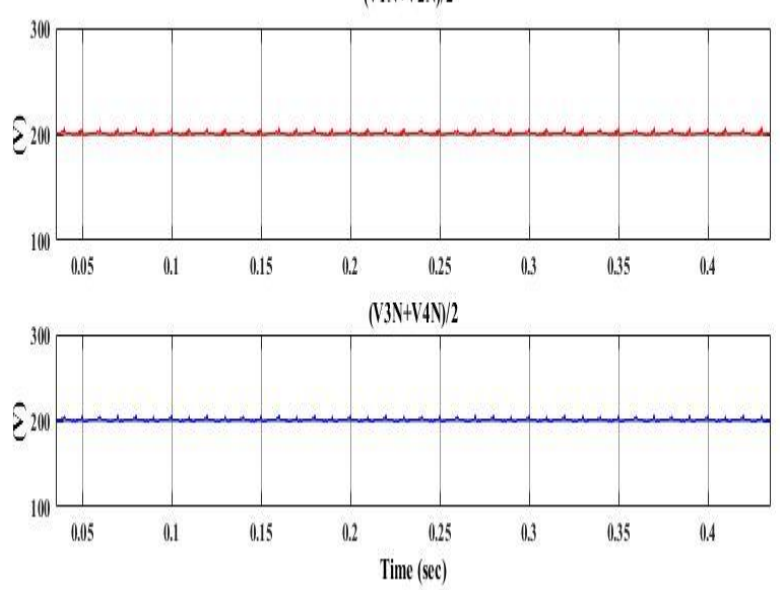

Fig.14.Common Mode characteristics of the H6topology

The Characteristics of $\mathrm{CM}$ voltages for $\mathrm{H} 6$ converter topology with pure real and reactive powers are expressed as; for positive half cycle of $\mathrm{CM}$ voltage $\left(\mathrm{V}_{1 \mathrm{~N}}+\mathrm{V}_{2 \mathrm{~N}}\right) / 2$ and for negative half cycle of $C M$ voltage $\left(\mathrm{V}_{3 \mathrm{~N}}+\mathrm{V}_{4 \mathrm{~N}}\right) / 2$.

The characteristics of $C M$ Voltages $\left(\mathrm{V}_{1 \mathrm{~N}}, \mathrm{~V}_{2 \mathrm{~N}}, \mathrm{~V}_{3 \mathrm{~N}}\right.$ and $\mathrm{V}_{4 \mathrm{~N}}$ ) are depicts in figure 14. Due to fluctuation in CM voltage. However, the peak and RMS value of leakage current flows through this topology depicts in figure 15.

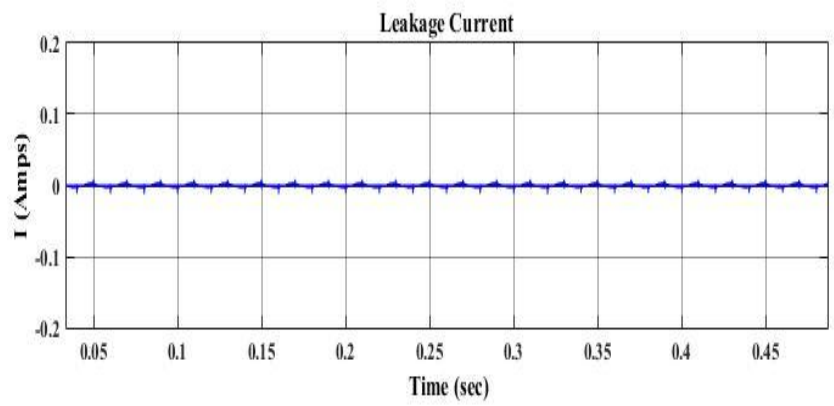

Fig 15.Simulation Result for Leakage Current 

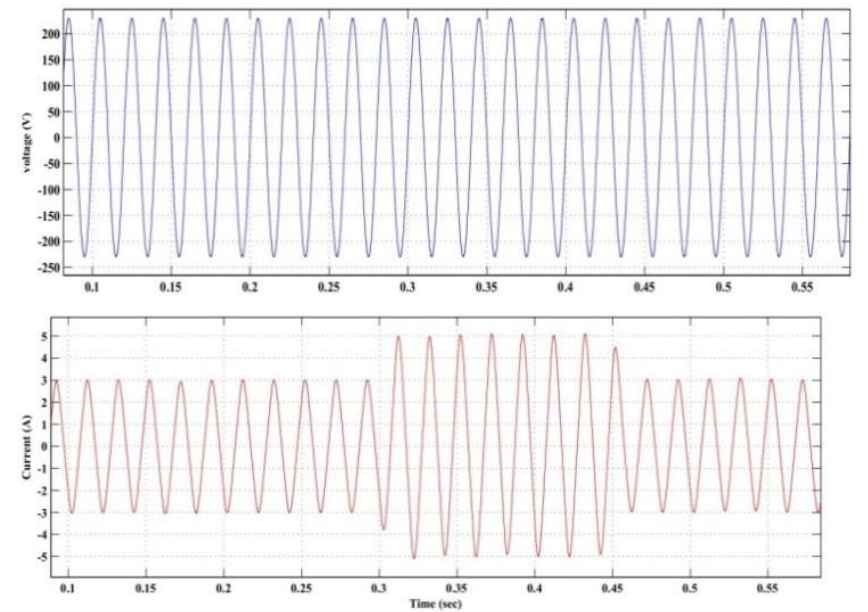

Fig.16. Performance of Grid Voltage and Current
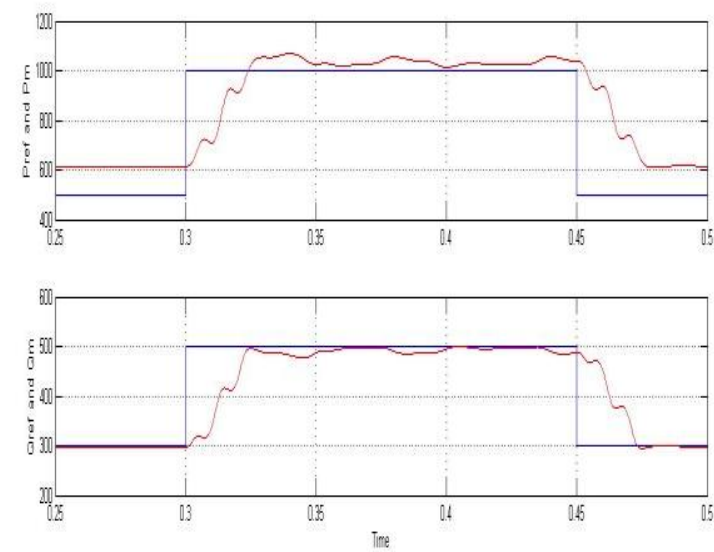

Fig.17. Performance of Grid active and Reactive Powers

The dynamic performance of the projected system is computer-generated under changes in both Pref and Qref. The simulation results of Grid Voltage and Current and its measured active and reactive powers are shown in figure 16 and 17 respectively.

From the results, it shows that there is a change in grid current with respect to step variation in load and active and reactive powers tracks the reference powers. From the results, there is very low distortion in grid voltage and current, hence the leakage current flows over the system is also very low

\section{CONCLUSIONS}

This paper Suggests the system to govern the direction of current from Photo voltaic system to grid be governed byANN controller. Photo Voltaic system combines with inverter structure and the regulation isdevelopingby using MATLAB / Simulink setting. By appropriatestrategy of ANN with Proportional Resonant controller, the H6 PV inverter had do well in producing aexceptionalcomeback, where, final current of inverter is sinusoidal and harmonic value is to beencountered with international standards. Finally, Simulated Results are analyzed.

Additionally, this topology has the following advantage

1. The simulatedH6 topologyhad abilityofinjecting reactive power to the grid with low harmonicdistortion.
2. CM voltage is retained same during the whole grid period. Consequently, the leakage current is well intimidated.

3. Higher performance can be found by presenting super junction MOSFETs for alldevices which have frequency $20,000 \mathrm{~Hz}$ operation is permissible to decline the ripple in current of finaland passive elements dimension.

\section{REFERENCES}

1. Monirul Islam, Nadia Afrin, and SaadMekhilef, Senior Member, IEEE "Efficient Single Phase Transformerless Inverter for Grid-Tied PVG System with Reactive Power Control,” IEEE Transactions On Sustainable Energy, 2016.

2. X. Huafeng and X. Shaojun, "Leakage current analytical model and application in single-phase transformerless photovoltaic Grid connected inverter" IEEE Trans. Electromagn. Compat., vol. 52, no. 4, pp. 902-913, Nov. 2010.

3. T. Kerekes, R. Teodorescu, P. Rodriguez, G. Vazquez, and E. Aldabas, "A new high-efficiency single-phase transformerless PV inverter topology," IEEE Trans. Ind. Electron., vol. 58, no. 1, pp 184-191, Jan. 2011

4. Y. Bo, L. Wuhua, G. Yunjie, C. Wenfeng, and H. Xiangning, "Improved transformerless inverter with common-mode leakage current elimination for a photovoltaic grid-connected power system," IEEE Trans. Power Electron., vol. 27, no. 2, pp.

5. 752-762, Feb. 2012.

6. O. Lopez et al., "Eliminating ground current in a transformerless photovoltaic application," IEEE Trans. Energy Convers.,vol. 25, no. 1, pp. 140-147, Mar. 2010.

7. T. F. Wu, C. L. Kuo, K. H. Sun, and H. C. Hsieh, "Combined unipolar and bipolar PWM for current distortion improvement during power compensation," IEEE Trans. Power Electron., vol. 29, no. 4, pp. 1702-1709, Apr. 2014.

8. D. Schmidt, D. Siedle, and J. Ketterer, "Inverter for transforming a DC voltage into an AC current or an AC voltage," EP Patent 1, 369, 985, 2009

9. M. Victor, F. Greizer, S. Bremicker, and U. Hübler, "Method of converting a direct current voltage from a source of direct current voltage, more specifically from a photovoltaic source of direct current voltage, into a alternating current voltage," U.S. Patents 7411802 B2, 2008

10. M. Islam and S. Mekhilef, "An improved transformerless grid connected photovoltaic inverter with reduced leakage current," Energy convers.Manage, vol. 88, pp. 854-862, 2014

11. E. Gubía, P. Sanchis, A. Ursúa, J. López, and L. Marroyo, "Ground currents in single-phase transformerless photovoltaic systems," Progr. Photovoltaics Res. Appl., vol. 15, pp. 629-650, 2007.

12. S. Dasgupta, S. K. Sahoo, and S. K. Panda, "Single-phase inverter control techniques for interfacing renewable energy sorces with micro grid part I: Parallel-connected inverter topology with active and reactive power flow control along with grid current shaping," IEEE Trans. Power Electron., vol. 26, no. 3, pp. 717-731, Mar. 2011

13. Monirul Islam, Nadia Afrin, and SaadMekhilef, Senior Member, IEEE "Efficient Single Phase Transformerless Inverter for Grid Tied PVG system with Reactive power control,” IEEE Transactions On Sustainable Energy,2016.

14. M. Monfared and S. Golestan, "Control strategies for single-phase grid integration of small-scale renewable energy sources: A review," Renew. Sustain. Energy Rev., vol. 16, pp. 4982-4993, 2012

15. F. Blaabjerg, R. Teodorescu, M. Liserre, and A. V. Timbus, "Overview of control and grid synchronization for distributed power generation systems,'IEEE Trans. Ind. Electron., vol. 53, no. 5, pp. 1398-1409, Oct. 2006

16. S. Lalouni, D. Rekioua, T. Rekioua, and E. Matagne, "Fuzzy logic control of stand-alone photovoltaic system with battery storage," Journal Power. Sources, vol. 193, pp. 899-907, Sep 2009

17. D. P. Kaundinya, P. Balachandra, and N.H. Ravindranath, "Grid connected versus stand-alone energy systems for decentralized power-A review of literature," Renew. Sust. Energy Rev., vol. 13, pp, October 2009

18. Y. Yang and F. Blaabjerg, "Low-voltage ride-through capability of a single-stage single-phase photovoltaic system connected to the lowvoltage grid,'Int. J. Photoenergy, vol. 2013, pp. 1-9, 2013 